\section{Check for updates}

Cite this: RSC Adv., 2018, 8, 12619

\title{
Synthesis, characterization, aggregation-induced emission, solvatochromism and mechanochromism of fluorinated benzothiadiazole bonded to tetraphenylethenes $\uparrow$
}

\begin{abstract}
Chin-Yang Yu, (DD* Chia-Chieh Hsu and Hsi-Chen Weng
Compounds consisting of unsubstituted, monofluoro and difluoro substituted benzothiadiazole bonded to two tetraphenylethenes were successfully prepared by palladium catalyzed Suzuki-Miyaura cross-coupling reaction of their corresponding co-monomers. All compounds exhibited aggregation-induced emission characteristics when the water fraction was higher than $60 \%$ in the THF/water mixtures. The emission maximum for the three compounds was blue-shifted when the water content reached $90 \%$ compared to that in THF solution. The intensity of emission maximum of difluorinated benzothiadiazole linked with two tetraphenylethenes was 2.5 times higher in $90 \%$ water compared to those in THF solution. Surprisingly, two liquid crystal phases with two distinct emission colors were observed only for the compound containing difluorinated benzothiadiazole bonded to two tetraphenylethene. All compounds showed remarkable solvatochromic properties in selected solvents with different polarities. The powder XRD results and mechanochromism of the compounds suggested that the solid state structures can change from one form to another by grinding, fuming or annealing processes.
\end{abstract}

Received 15th February 2018

Accepted 28th March 2018

DOI: $10.1039 / \mathrm{c} 8 \mathrm{ra01448e}$

rsc.li/rsc-advances aggregation induced emission characteristics. Very recently, the TPE based molecules have been synthesized and investigated by Misra et al. ${ }^{16-18}$ The rational molecular design of the TPE based molecules makes it potential uses in non-doped OLEDs with a good color contrast. In addition, the obvious color change ranging from blue to red with reversible mechanochromism based on molecules containing the TPE linked to a variety of electron acceptors has also been demonstrated.

Typically, the emission colors of conjugated carbocyclic compounds with AIE characteristics are between blue and green. ${ }^{19}$ In fact, the emission colors of compounds can be altered through molecular design such as when the structures contain electron donor-acceptor (D-A) units and heteroatoms. In addition, the rational design and synthesis of $\mathrm{D}-\mathrm{A}$ molecules could realize full visible colors by manipulating the strength of intramolecular charge transfer (ICT) between the constituent units. ${ }^{20}$ Benzothiadiazole (BT) is one of the most important classes of electron acceptors due to its relatively high electron affinity and $\pi$-extended planar structure. ${ }^{21}$ Recently, fluorination of BT has been utilized and shown to be an efficient means to modify the optical, electronic and electrochemical properties of BT. ${ }^{22,23}$ Tang and coworkers have synthesized the electron donor-acceptor-donor (D-A-D) chromophores containing BT derivatives and TPE. ${ }^{24}$ These molecules exhibit high emission with different emission colors in the solid state. The other asymmetrical D-A or D-A-D types of chromophores such as cyano-substituted diphenylethene derivatives with AIE 
characteristics, vapochromic and mechanochromic properties have also been reported. ${ }^{25-27}$ The compounds revealed a reversible conversion between the crystalline and amorphous forms by different processes.

Solvatochromism is the ability of compounds to change color when dissolved in different solvents. ${ }^{28,29}$ Recently, a variety of solvatochromic molecules with D-A structures including symmetrical or asymmetrical benzothiadiazide based cyanosubstituted diphenylethene derivatives ${ }^{26,30,31}$ have been synthesized and studied due to their applicability as probes for the determination of volatile solvent vapor as well as their potential application in optical recording and security papers. These compounds exhibit remarkable solvatochromic and vapochromic characteristics by conjugation effects, molecular packing and conversion of crystalline to amorphous states. Mechanofluorochromic materials are a sort of smart material which display a changing color of emission in response to external stimuli and these materials can be potentially used in memory chips, security ink and sensors. ${ }^{32-34}$ Araki and coworkers have reported that organic mechanofluorochromic compounds exhibited piezochromic luminescence by controlling the mode of molecular packing. ${ }^{35}$ Mechanofluorochromism of donoracceptor $\pi$-conjugated (D- $\pi-\mathrm{A}$ ) fluorescent dyes was attributed to a reversible switching between crystalline and amorphous states with a change in the dipole-dipole and intermolecular $\pi$ $\pi$ interactions. ${ }^{36,37}$ Secondary bonding interactions and $\mathrm{D}-\mathrm{A}$ pairs play important roles in the design of new mechanochromic materials. ${ }^{38-40}$ Recently, a number of D-A compounds have been prepared and found to possess mechanofluorochromic nature. ${ }^{41-43}$

In general, D-A type molecular systems show low fluorescence quantum efficiency in solution as well as in the solid state. Although the AIE active molecules containing BT bonded to two TPE with remarkable mechanochromism have been reported and investigated by Misra, ${ }^{44}$ no examples of fluorinated substituted BT bonded to two TPE are available. The modification of the fluorine atoms onto the BT unit seems to be an efficient way that the molecules can be easily prepared and the optical, electronic and electrochemical properties as well as aggregation-induced emission characteristics, solvatochromism and mechanochromism can be fine-tuned which can compare to that of the unsubstituted BT bonded to two TPE. The aim of this research work is mainly to investigate the properties and the effect of fluorine atoms attached to the central BT unit of D-A-D type molecular systems as well as their aggregation-induced emission characteristics, solvatochromism and mechanochromism. In this work, we report the synthesis of unsubstituted, monofluoro and difluoro substituted BT bonded to two TPE by palladium catalyzed Suzuki-Miyaura cross-coupling reaction of their corresponding comonomers. The structures of the D-A-D types of three chromophores have been fully characterized. Aggregation induced emission characteristics of small molecules in the THF/water mixtures and in the solid state have been studied as well as their solvatochromic and mechanochromic effects related to their structures.

\section{Results and discussion}

\section{Synthesis and characterization of BT-2TPE, FBT-2TPE and 2FBT-2TPE}

The synthetic routes towards the D-A-D types of molecules BT2TPE, FBT-2TPE and 2FBT-2TPE are shown in Scheme 1. Fluorinated phenylenediamine derivatives were reacted with thionyl chloride $\left(\mathrm{SOCl}_{2}\right)$ in the presence of triethylamine in anhydrous chloroform to afford the fluorinated 2,1,3-benzothiadiazole derivatives 1 and 2. A high selectivity of bromination at the 4 and 7 position of 1 and 2 was carried out by the dropwise addition of bromine in hydrobromic acid containing 1 or 2 to give 3 and 4. The 4-(1,2,2-triphenylvinyl)phenylboronic acid pinacol ester 5 was prepared by a modification of a procedure reported previously. ${ }^{45}$ The D-A-D types of molecules BT-2TPE, FBT-2TPE and 2FBT-2TPE were synthesized by Suzuki-Miyaura cross-coupling reaction using equimolar amounts of the corresponding comonomers, $10 \mathrm{~mol} \% \mathrm{Pd}\left(\mathrm{PPh}_{3}\right)_{4}$ and aqueous $\mathrm{K}_{2} \mathrm{CO}_{3}$ to give BT-2TPE, FBT-2TPE and 2FBT-2TPE in a yield of $85 \%$, $64 \%$ and $38 \%$, respectively.

The compounds BT-2TPE, FBT-2TPE and 2FBT-2TPE were fully characterized by ${ }^{1} \mathrm{H}$ NMR, ${ }^{13} \mathrm{C}$ NMR, ${ }^{19} \mathrm{~F} N M R,{ }^{1} \mathrm{H}-{ }^{1} \mathrm{H}$ COSY spectroscopy and high resolution mass spectrometry (see ESI $\dagger$ ). Clearly, a low isolated yield of compounds FBT-2TPE and 2FBT2TPE was obtained compared to that of BT-2TPE possibly due to the low reactivity of the fluorinated BT moieties as the introduction of the fluorine atom to the BT leads to a deactivation of the aromatic ring.

Compounds BT-2TPE, FBT-2TPE and 2FBT-2TPE were characterized by ${ }^{1} \mathrm{H}$ NMR spectroscopy in $\mathrm{CD}_{2} \mathrm{Cl}_{2}$ (Fig. 1). A singlet peak at $7.74 \mathrm{ppm}$ integrating to 2 hydrogens corresponds to the hydrogens of BT unit for BT-2TPE (Fig. 1a). Two $\mathrm{AA}^{\prime} \mathrm{BB}^{\prime}$ systems at around 7.78 and $7.20 \mathrm{ppm}$ integrating to 4 hydrogens each were assigned to the hydrogens of TPE relative to ortho and meta position of carbons linked to the BT moieties, respectively. The multiple signals between 7.05 and $7.18 \mathrm{ppm}$ integrating to 30 hydrogens were attributed to the remaining hydrogens of the TPE. The doublet at around $7.63 \mathrm{ppm}\left(\mathrm{J}_{\mathrm{H}-\mathrm{F}}=11.8 \mathrm{~Hz}\right)$ integrating to 1 hydrogen was assigned to the hydrogen of BT unit

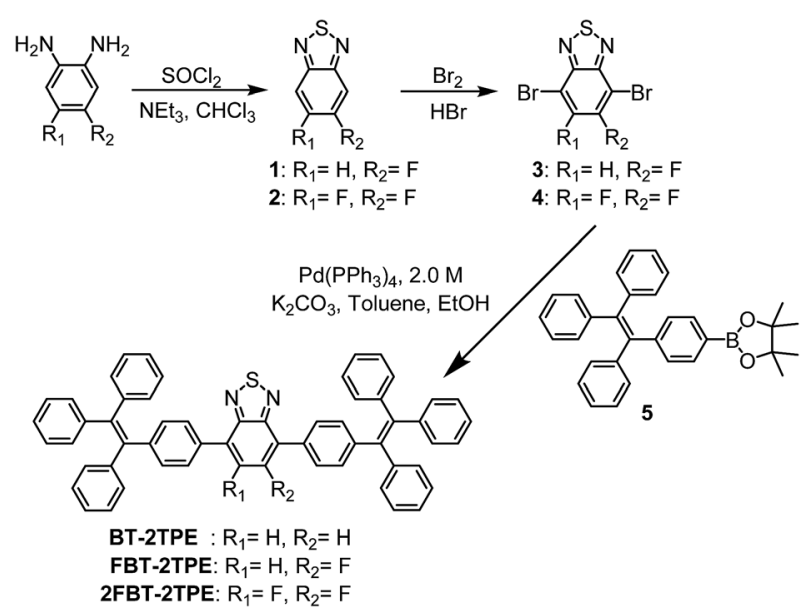

Scheme 1 Synthetic routes to BT-2TPE, FBT-2TPE and 2FBT-2TPE. 

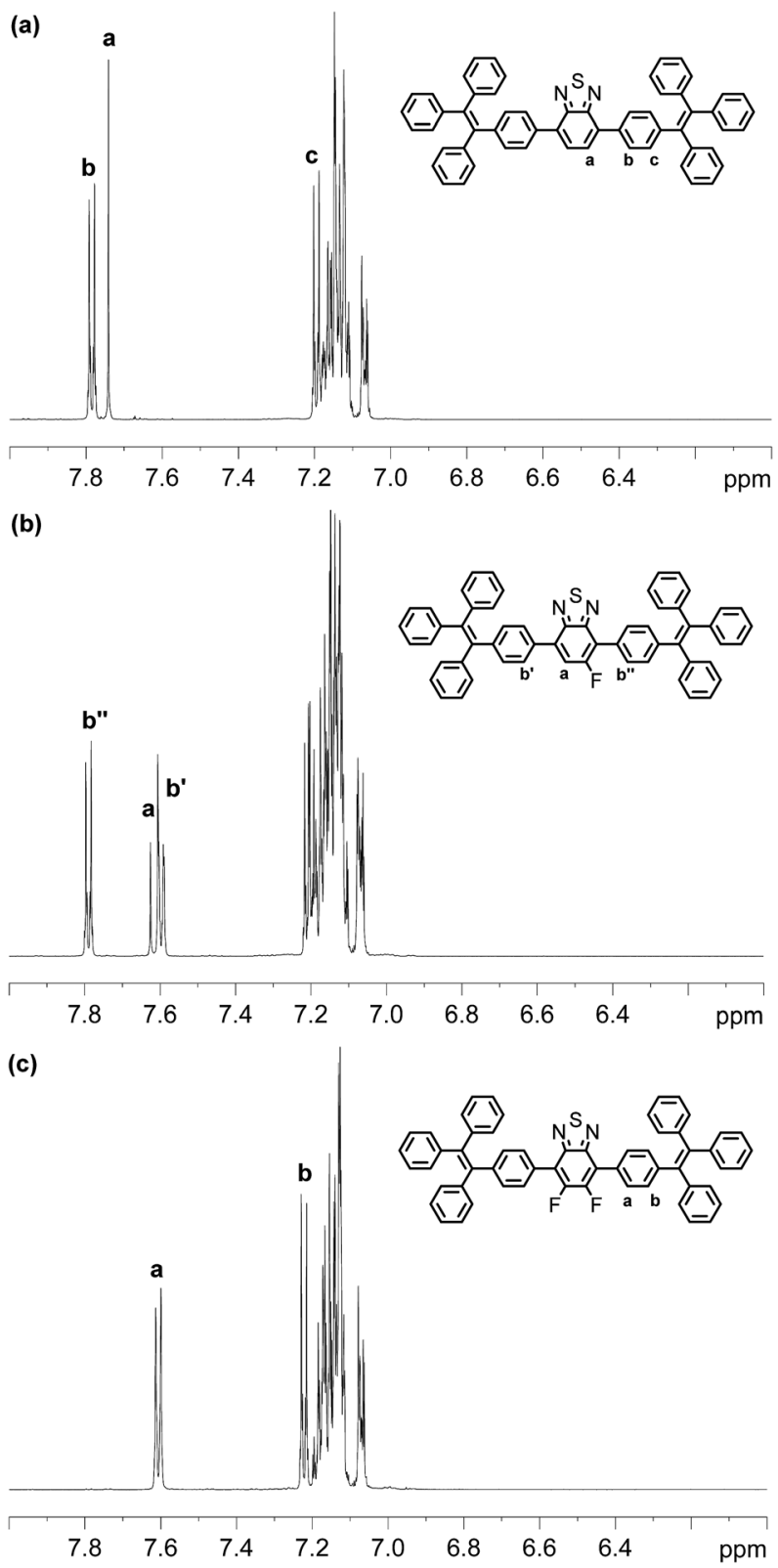

Fig. $1{ }^{1} \mathrm{H}$ NMR spectra of BT-2TPE, FBT-2TPE and 2FBT-2TPE in $\mathrm{CD}_{2} \mathrm{Cl}_{2}$.

relative to the ortho position of carbon linked to fluorine atom in FBT-2TPE (Fig. 1b). The two $\mathrm{AA}^{\prime} \mathrm{BB}^{\prime}$ systems at 7.79 and $7.60 \mathrm{ppm}$ integrating to 2 hydrogens each were attributed to the hydrogens of phenyl ring of TPE moieties relative to the ortho position of carbon linked to BT units. The multiple signals between 7.04 and $7.23 \mathrm{ppm}$ integrating to 34 hydrogens were attributed to the remaining hydrogens of the TPE. The multiple signals appearing at 7.61 and $7.22 \mathrm{ppm}$ (two $\mathrm{AA}^{\prime} \mathrm{BB}^{\prime}$ systems) integrating to 4 hydrogens each correspond to the hydrogens of the phenyl ring relative to the ortho and the meta position of carbons attached to the difluoro-substituted BT, respectively (Fig. 1c). Again, the multiple signals between 7.05 and $7.20 \mathrm{ppm}$ integrating to 30 hydrogens are attributed to the remaining hydrogens of the TPE.

\section{Optical properties of BT-2TPE, FBT-2TPE and 2FBT-2TPE}

The UV-vis absorption spectra of BT-2TPE, FBT-2TPE and 2FBT2TPE were recorded in dilute dichloromethane $\left(5 \times 10^{-6} \mathrm{M}\right)$ (Fig. 2a). The band between 280 and $350 \mathrm{~nm}$ can be attributed to the $\pi-\pi^{*}$ transition and another band between 360 and $470 \mathrm{~nm}$ corresponds to the charge transfer (CT) transition between the TPE and the BT units. ${ }^{46}$ The absorption maximum of BT-2TPE, FBT-2TPE and 2FBT-2TPE is at 414, 405 and $391 \mathrm{~nm}$, respectively. The absorption maximum was blue-shifted after the introduction of the fluorine atom onto the BT possibly due to a collapsing of the planarity of the molecules. The emission maximum wavelength of BT-2TPE, FBT-2TPE and 2FBT-2TPE in dilute dichloromethane $\left(5 \times 10^{-6} \mathrm{M}\right)$ (Fig. $\left.2 \mathrm{~b}\right)$ is very similar at around $553 \mathrm{~nm}$. Thin films of BT-2TPE, FBT-2TPE and 2FBT2TPE were prepared by spin-coating $150 \mu \mathrm{L}$ of the solution $(3 \mathrm{mg}$ $\mathrm{mL}^{-1}$ in toluene) onto glass slides $(2.0 \mathrm{~cm} \times 2.0 \mathrm{~cm})$ at a rotation speed of $1500 \mathrm{rpm}$ for 20 seconds and then $3000 \mathrm{rpm}$ for 20 seconds. The solid state absorption maximum of BT-2TPE, FBT2TPE and 2FBT-2TPE was red-shifted by 30, 24 and $26 \mathrm{~nm}$, respectively compared to that of the solution. This bathochromic shift can be attributed to intermolecular interactions in the solid state as we expected. However, the solid state emission maximum wavelength of BT-2TPE, FBT-2TPE and 2FBT-2TPE is blue-shifted by 18,26 and $38 \mathrm{~nm}$ compared to that of the solution. The optical bandgap calculated by the onset of the absorption edge of BT-2TPE, FBT-2TPE and 2FBT-2TPE is $2.35,2.40$ and $2.46 \mathrm{eV}$, respectively. The introduction of
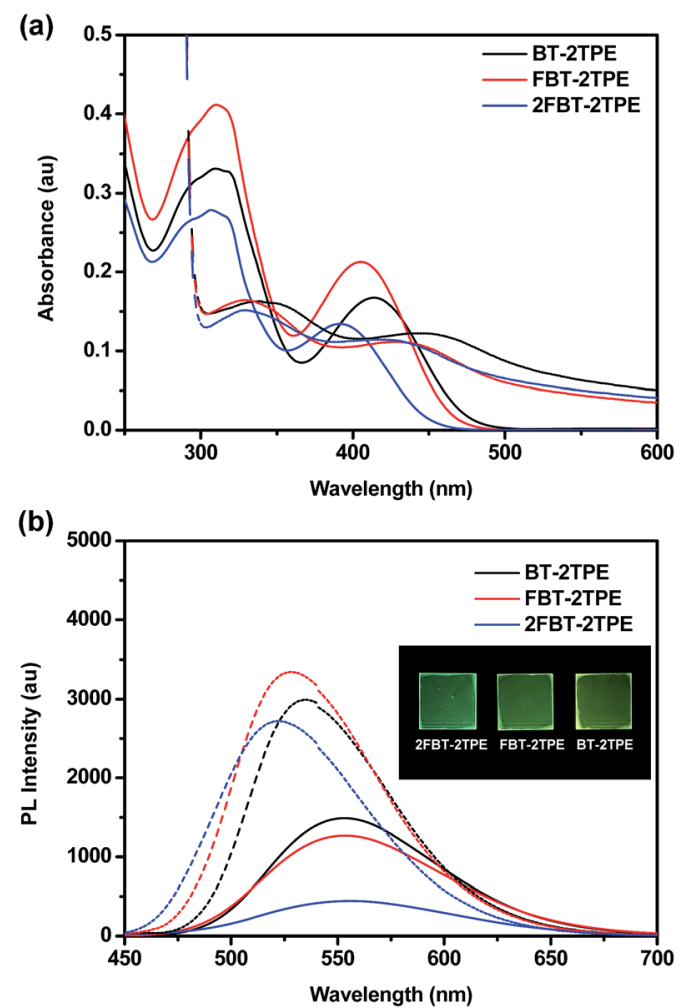

Fig. 2 (a) UV-Vis spectra and (b) emission spectra of BT-2TPE, FBT2TPE and 2FBT-2TPE in dichloromethane solution (solid line) and in solid state (dashed line). Pictures of films under UV light irradiation at a wavelength of $365 \mathrm{~nm}$ are shown in the insets. 
a fluorine atom onto the BT units leads to a collapse of the planarity of the molecules, therefore the optical bandgap increases as we expected. The details of the absorption and emission maximum, quantum yield, Stokes shift and optical bandgap are shown in the ESI (Table S1†).

The emission spectra of compounds BT-2TPE, FBT-2TPE and 2FBT-2TPE with different water fractions in THF/water mixture are shown in Fig. 3a-c. Upon increasing the water fraction up to $60 \%$, the maximum emission wavelength of BT-2TPE, FBT-2TPE and 2FBT-2TPE was red-shifted by 15, 18 and $23 \mathrm{~nm}$, respectively and the maximum emission intensity gradually decreases. This could be attributed to the stabilization of the intramolecular charge-transfer state upon increasing the polarity of the solvents. ${ }^{\mathbf{4 6 , 4 7}}$ However, upon a further increase in the water fraction from $60 \%$ to $90 \%$, the maximum emission wavelength of BT-2TPE, FBT-2TPE and 2FBT-2TPE was blue-shifted and the maximum emission intensity generally increases due to formation of nanoaggregates that can enhance aggregationinduced emission. All compounds showed distinct responses in different THF and water percentages. At lower water fractions $(<60 \%)$, the emission is mainly attributed to intramolecular charge transfer between the electron donor and the electron acceptor which is controlled by solvent polarity, however, at higher water contents $(>60 \%)$, AIE dominates over solvent polarity. The maximum photoluminescence quantum yield of compounds BT-2TPE, FBT-2TPE and 2FBT-2TPE (Fig. 3d) is $0.24,0.29$ and 0.31 , respectively compared to quinine sulfate (0.546) in $0.1 \mathrm{M} \mathrm{H}_{2} \mathrm{SO}_{4}$. It should be noted that the emission maximum intensity of 2FBT-2TPE (Fig. 3e) in 90\% water content
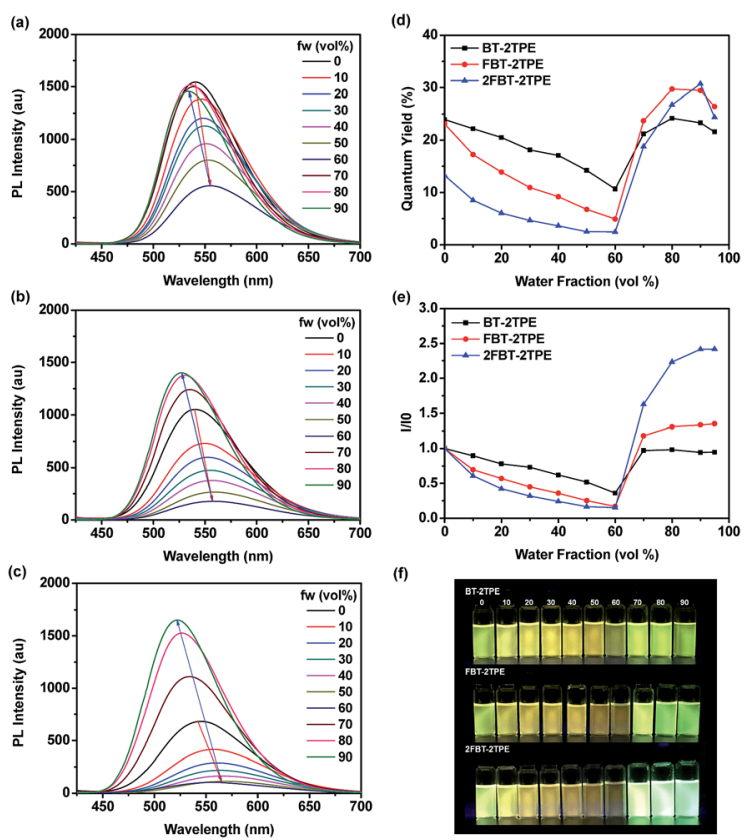

Fig. 3 Emission spectra of (a) BT-2TPE, (b) FBT-2TPE and (c) 2FBT2TPE in THF-water mixtures (concentration:5 $\mu \mathrm{M}$; excitation wavelength: $\left.\lambda_{\max }\right)$ and plots of (d) fluorescence quantum yields and (e) $I / I_{0}$ vs. water fraction of BT-2TPE, FBT-2TPE and 2FBT-2TPE and (f) pictures of BT-2TPE, FBT-2TPE and 2FBT-2TPE in different THF-water mixtures under UV light irradiation at a wavelength of $365 \mathrm{~nm}$. was 2.5 times higher than that of in THF solution. The pictures of BT-2TPE, FBT-2TPE and 2FBT-2TPE in different THF-water mixtures under UV light irradiation at a wavelength of $365 \mathrm{~nm}$ is shown in Fig. 3f. All compounds BT-2TPE, FBT-2TPE and 2FBT-2TPE showed emission color changes upon increases in the fraction of water.

\section{Single crystal structure of 2FBT-2TPE}

In order to obtain a single crystal of 2FBT-2TPE, a saturated dichloromethane solution was allowed to slowly evaporate at room temperature. The solid state structure of 2FBT-2TPE (Fig. 4a) showed symmetrical disorder in the BT core (space group: $P 1, Z=1$ ) and solvent packing in the crystal structure. The crystal structure of 2FBT-2TPE confirmed that the dihedral angles between BT and phenyl rings of TPE were $46.32^{\circ}$ and $46.48^{\circ}$, respectively which are relatively large due to the highly twisted structure of 2FBT-2TPE. The packing diagram of 2FBT2TPE (Fig. 4b) showed the intermolecular distance of $\mathrm{C}-\mathrm{H} \cdots \mathrm{S}$ was $2.945 \AA$ from the disordered sulfur atom, the intermolecular distance of $\mathrm{C}-\mathrm{H} \cdots \mathrm{F}$ was 3.038 and $3.134 \AA$ from the disordered fluorine atom and intramolecular distance of C-H $\cdots$ F was 2.553 and $2.663 \AA$. The packing structure of 2FBT2TPE (Fig. 4c) exhibited a ladder-like packing structure with a distance of 4.811 and $4.349 \AA$. An attempt to acquire the single crystal of BT-2TPE and FBT-2TPE failed possibly due to the

(a)

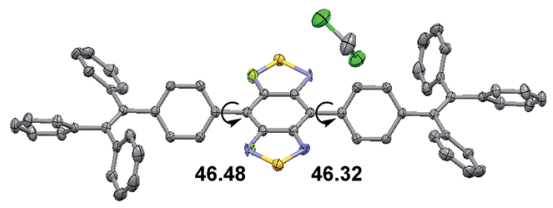

(b)

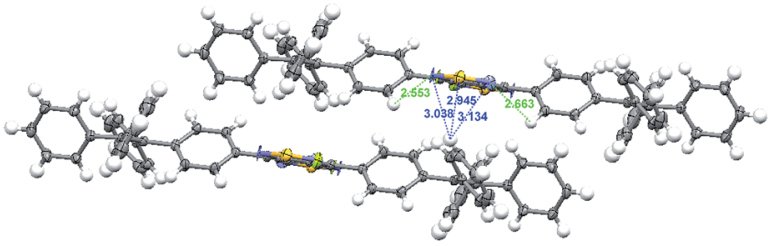

(c)

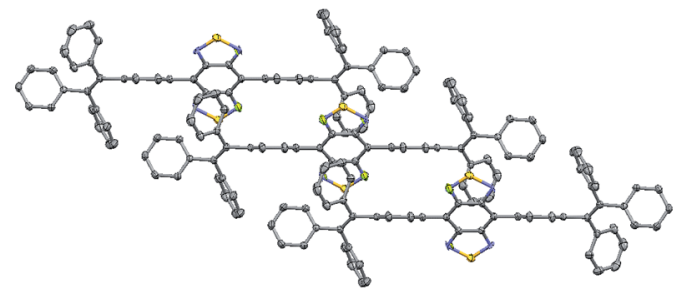

Fig. 4 (a) Solid-state structures, (b) inter- and intramolecular distances and (c) packing diagram of 2FBT-2TPE. Thermal ellipsoids are set at $50 \%$ probability. 
highly random nature of the unsubstituted and monofluorinated substituted BT.

\section{Thermal properties of BT-2TPE, FBT-2TPE and 2FBT-2TPE}

The decomposition temperatures of BT-2TPE, FBT-2TPE and 2FBT-2TPE were determined by thermal gravimetric analysis (TGA) at a heating rate of $10{ }^{\circ} \mathrm{C} \mathrm{min}^{-1}$ under a nitrogen flow. Clearly, one step weight loss was observed for all compounds (Fig. 5a). The 5\% weight loss of BT-2TPE, FBT-2TPE and 2FBT2TPE was at $408{ }^{\circ} \mathrm{C}, 416^{\circ} \mathrm{C}$ and $402{ }^{\circ} \mathrm{C}$, respectively with a small amount of solid residue remaining when heating up to $800{ }^{\circ} \mathrm{C}$. All compounds exhibited an excellent thermal stability. The DSC traces of BT-2TPE, FBT-2TPE and 2FBT-2TPE at the second heating cycle (Fig. 5b) showed an endothermic peak at 266, 260, $310^{\circ} \mathrm{C}$ with an enthalpy value of $68.0,46.6$ and $17.5 \mathrm{~kJ} \mathrm{~mol}^{-1}$, respectively which can be attributed to the melting point of the compounds. In addition, two broad exothermic transitions for BT-2TPE at 172 and $224{ }^{\circ} \mathrm{C}$ were observed upon heating corresponding to the formation of a self-organized structure. The polarized optical micrographs associated with different transitions for 2FBT-2TPE were shown in the insets of Fig. 5b. There are an additional two endothermic peaks at 293 and $303{ }^{\circ} \mathrm{C}$ for 2FBT-2TPE which can be attributed to the two transitions related to the two distinct liquid crystal mesophases observed

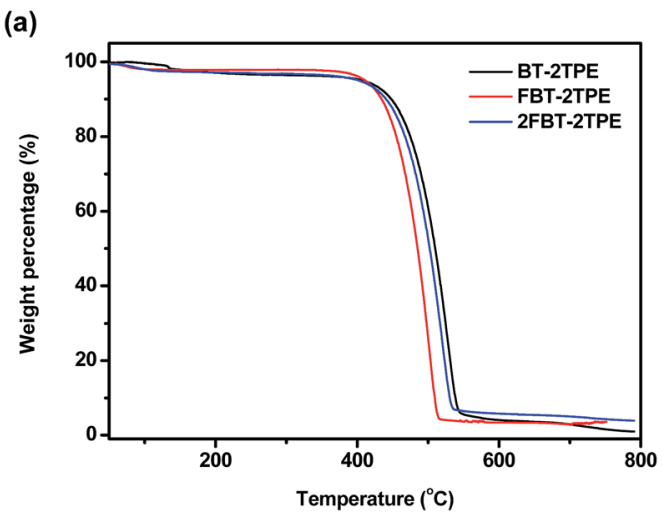

(b)

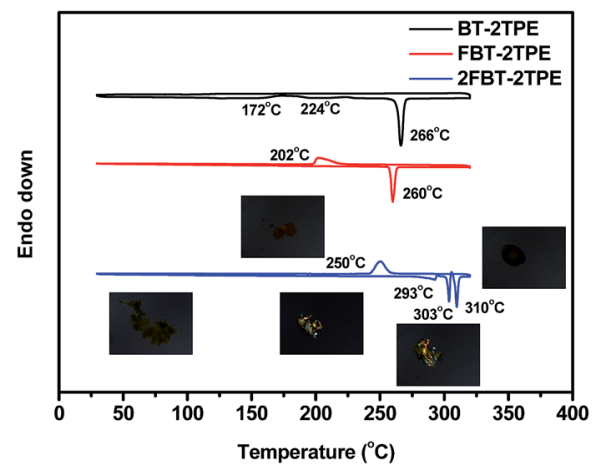

Fig. 5 (a) TGA curves of BT-2TPE, FBT-2TPE and 2FBT-2TPE at a heating rate of $10{ }^{\circ} \mathrm{C} \mathrm{min}^{-1}$ under a nitrogen atmosphere and (b) DSC diagrams of the second heating and cooling curves of BT-2TPE, FBT2TPE and 2FBT-2TPE at a heating and cooling rate of $10{ }^{\circ} \mathrm{C} \mathrm{min}-1$ under a nitrogen atmosphere. Polarized optical micrographs associated with the transition temperature of 2FBT-2TPE are shown in the insets. by polarized optical microscopy with a heating rate of 2 ${ }^{\circ} \mathrm{Cmin}^{-1}$. Upon cooling, the recrystallization temperature of FBT-2TPE and 2FBT-2TPE was observed at 202 and $250{ }^{\circ} \mathrm{C}$, respectively. No recrystallization temperature for BT-2TPE could be observed possibly due to the random nature of BT-2TPE.

\section{Solvatochromic behaviors}

In general, the spectral properties of $\mathrm{D}-\mathrm{A}$ molecules are sensitive towards the solvent polarity. In order to study the solvatochromic effect of BT-2TPE, FBT-2TPE and 2FBT-2TPE, various solvents with different polarities such as hexane, toluene, chloroform, dichloromethane, ethyl acetate, 1,4dioxane, acetone, acetonitrile, dimethylsufloxide and dimethylformaldehyde were selected. Compounds BT-2TPE, FBT2TPE and 2FBT-2TPE were soluble in all of the selected organic solvents and exhibited a pronounced solvatochromic performance. Generally, the absorption maximum of BT-2TPE, FBT2TPE and 2FBT-2TPE were all slightly blue-shifted when dissolved in a solvent of increasing polarity while the fluorescence maximum of BT-2TPE, FBT-2TPE and 2FBT-2TPE revealed a high degree of red-shifting with increasing solvent polarity. The emission maximum intensity gradually decreased, indicating that the larger charge separation and dipole moment existed in the excited state than in the ground state. The absorption spectra and emission spectra of BT-2TPE, FBT-2TPE and 2FBT-2TPE in different solvents and the solvatochromic

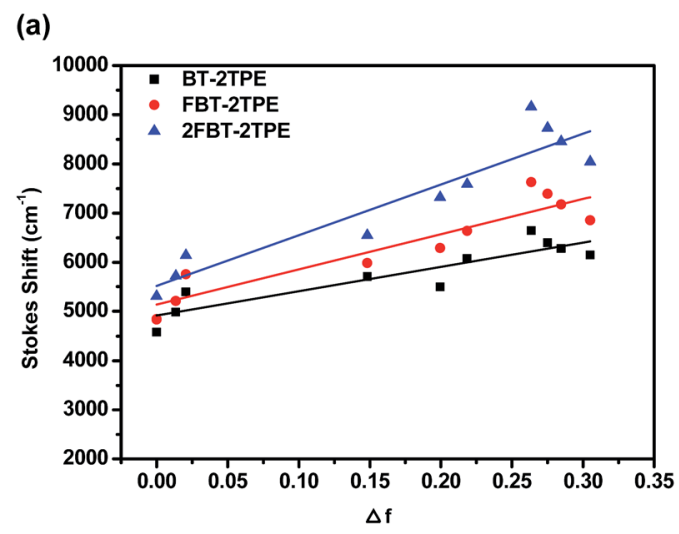

(b)

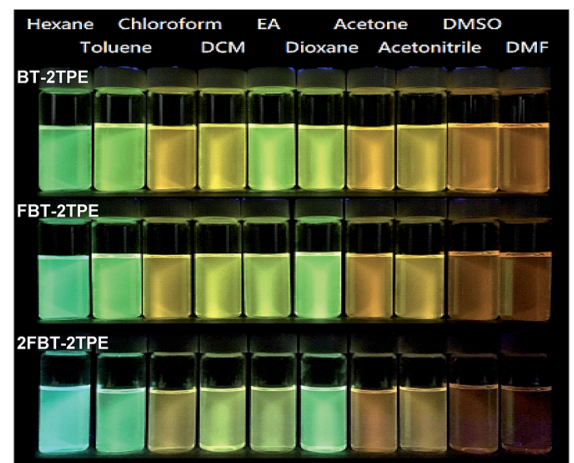

Fig. 6 (a) Plot of Stokes shift versus solvent polarity parameter of BT2TPE, FBT-2TPE and 2FBT-2TPE in various solvents and (b) pictures of BT-2TPE, FBT-2TPE, 2FBT-2TPE in different solvents under UV light at a wavelength of $365 \mathrm{~nm}$. 
behavior data have been summarized in the ESI (Fig. S32 and Table S3†). The plots of Stokes shift versus solvent polarity parameter based on the Lipper-Mataga equation of BT-2TPE, FBT-2TPE and 2FBT-2TPE were shown in Fig. 6a. As the solvent polarity parameter increases, the Stokes shift also increases with a linear correlation of 0.799 for BT-2TPE, 0.841 for FBT2TPE and 0.863 for 2FBT-2TPE. In addition, the calculated slope of fitting line for BT-2TPE, FBT-2TPE and 2FBT-2TPE was 4954, 7169 and 10 334, respectively. These results indicate that the fluorescent properties of three compounds are strongly related to the solvent polarity. Compound 2FBT-2TPE exhibited a relatively steep slope indicating the formation of large charge separation and high dipole moment in the excited state. Pictures of BT-2TPE, FBT-2TPE and 2FBT-2TPE in different solvents under UV light at a wavelength of $365 \mathrm{~nm}$ were shown in Fig. 6b. A notable color change of three compounds in different polarities of solvents was observed indicating a remarkable solvatochromism.

\section{Mechanochromic behaviors}

The ground samples were obtained from pristine powders via the grinding process using spatula, mortar and pestle. The annealed samples were obtained upon heating pristine powders at the specified temperature for $20 \mathrm{~min}$ and then allowing to slowly cool to room temperature. In this case, the annealing temperature for BT-2TPE, FBT-2TPE and 2FBT-2TPE was $200{ }^{\circ} \mathrm{C}$, $200{ }^{\circ} \mathrm{C}$ and $270{ }^{\circ} \mathrm{C}$, respectively. Surprisingly, the pristine powders BT-TPE obtained by evaporating dichloromethane and hexane exhibited a yellow and yellow-green color, respectively. The pristine powders FBT-2TPE and 2FBT-2TPE obtained by evaporating dichloromethane and hexane exhibited no color change upon visual inspection.

The mechanochromism of three compounds was investigated by emission spectroscopy. The emission spectra of compound BT-2TPE prepared by different processes were shown in Fig. 7a. Pristine powders obtained by evaporating dichloromethane exhibited an emission maximum at $545 \mathrm{~nm}$. After fuming with dichloromethane vapor for $5 \mathrm{~min}$, the emission maximum was at $515 \mathrm{~nm}$. In addition, after annealing the pristine powders for $20 \mathrm{~min}$, the emission maximum was at $513 \mathrm{~nm}$. Pristine powders obtained by evaporating dichloromethane via fuming or annealing process both exhibited a notable hypsochromic shift of around $30 \mathrm{~nm}$ with color changes from yellow to green (Fig. 7b) due to a decreased D-A interaction. Pristine powders obtained by evaporating hexane had an emission maximum at $514 \mathrm{~nm}$. After the grinding process, the ground compound revealed an emission maximum of $539 \mathrm{~nm}$ which was red-shifted by $25 \mathrm{~nm}$ with a color change from green to yellow (Fig. 7b) indicating an enhanced D-A interaction. Further annealing of the ground compound resulted in a shifting of the emission maximum to $516 \mathrm{~nm}$ with a color change from yellow to green. This suggested that conjugation or D-A interaction of compounds can be generated by simple grinding process which leads to a notable bathochromic shift. Powder X-ray diffraction (PXRD) measurements were employed to elucidate the micro-structures of the pristine

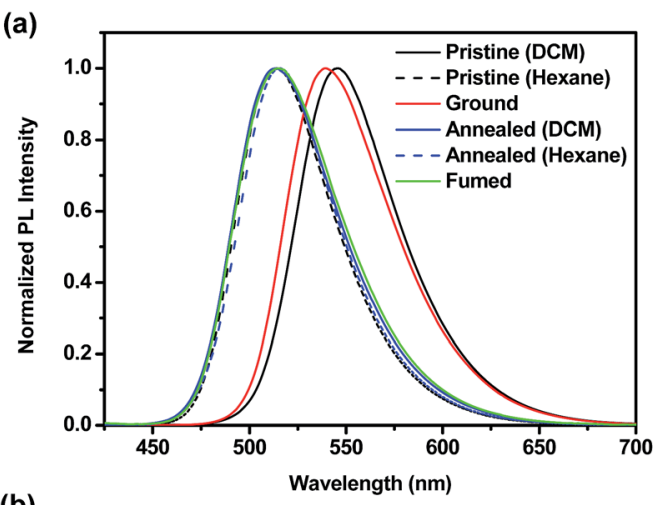

(b)

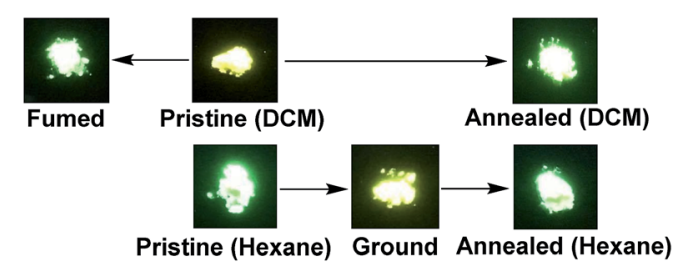

(c)

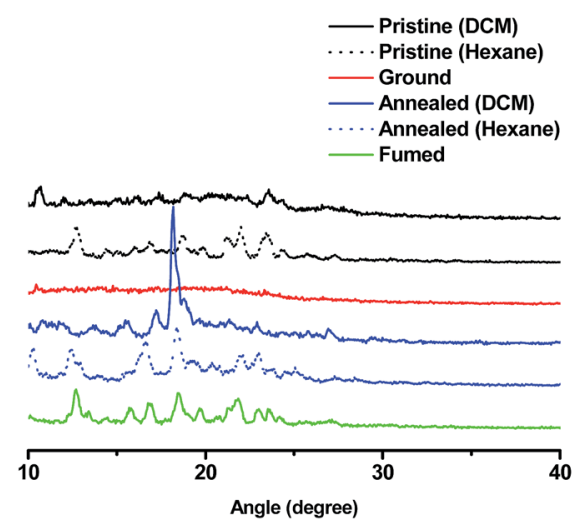

Fig. 7 (a) Normalized PL spectra (b) pictures and (c) PXRD diagrams of BT-2TPE in pristine, ground, annealed and fumed powders.

powders and powders through grinding and annealing process. PXRD results (Fig. 7c) revealed that fumed and annealed powders exhibited relatively sharp diffraction peaks compared to that of the pristine powders obtained by evaporating DCM indicating the generation of a crystalline form. Upon grinding pristine powders obtained by evaporating hexane, the sharp peaks disappeared suggesting a transition from the crystalline to the amorphous state. The ground powders were then annealed and the sharp diffraction peaks appeared again indicating the regeneration of the crystalline form.

The emission spectra of compounds FBT-2TPE and 2FBT2TPE as pristine, ground and annealed powders were shown in Fig. $8 \mathrm{a}$ and $\mathrm{b}$. The pristine, ground and annealed powders of FBT-2TPE exhibited an emission maximum at 512, 519 and $530 \mathrm{~nm}$, respectively. In addition, the pristine, ground and annealed powders of 2FBT-2TPE exhibited an emission maximum at 498, 509 and $484 \mathrm{~nm}$, respectively. It should be noted that a pronounced color change from green to blue after annealing of the ground compound 2FBT-2TPE was observed due to a decreased D-A interaction. PXRD results (Fig. 8c) for FBT-2TPE exhibited less intense diffraction peaks after the 

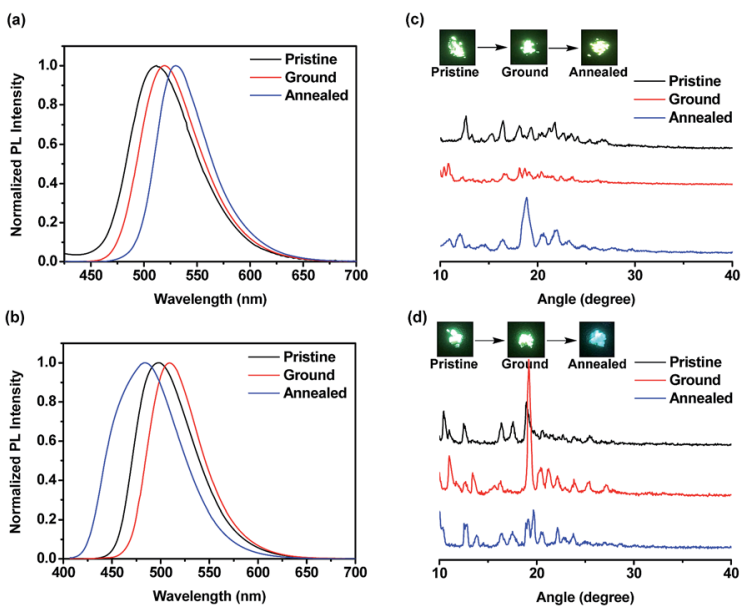

Fig. 8 Normalized PL spectra of (a) FBT-2TPE and (b) 2FBT-2TPE and PXRD results and photo images of (c) FBT-2TPE and (d) 2FBT-2TPE in pristine, ground and annealed powders. Photo images of pristine, ground and annealed powders FBT-2TPE and 2FBT-2TPE are shown in the insets.

grinding process and new sharp peaks generated by the annealed process indicating the transition from one crystalline form to amorphous state to another crystalline form. In addition, the ground powders of 2FBT-2TPE (Fig. 8d) showed relatively sharp diffraction peaks compared to pristine powders indicating the high degree of crystallinity. The ground samples were then annealed and a selection of low intensity and new peaks were observed possibly due to the conversion of one crystalline form to another. This suggests that compounds FBT2TPE and 2FBT-2TPE could form other types of well-organized structures by annealing and grinding processes, respectively compared to that of the pristine powders. ${ }^{35}$

\section{Experimental}

\section{Materials and general considerations}

All chemicals and reagents were purchased from commercial sources (Alfa Aesar, Acros and Sigma-Aldrich) without further purification. Solvents used for spectroscopic measurements were spectrograde. All air sensitive reactions were carried out under an argon or a nitrogen atmosphere. Anhydrous organic solvents were distilled under a nitrogen atmosphere over calcium hydride or sodium/benzophenone. Well-degassed solutions were carried out through bubbling argon for at least $30 \mathrm{~min}$. Column chromatography was performed using Silica Flash G60 70-230 mesh silica. ${ }^{1} \mathrm{H},{ }^{1} \mathrm{H}-{ }^{1} \mathrm{H}$ COSY,${ }^{1} \mathrm{H}^{13}{ }^{13} \mathrm{HSQC}$ and ${ }^{13} \mathrm{C}$ NMR spectra were recorded on Bruker AVIII HD-600 $\mathrm{MHz}$ spectrometer. The chemical shifts were reported in ppm. All coupling constants were reported in hertz $(\mathrm{Hz})$. The following abbreviations were used to indicate multiplicity: $\mathrm{s}=$ singlet, $\mathrm{d}=$ doublet, $\mathrm{dd}=$ doublet of doublets, $\mathrm{ddd}=$ doublet of doublet of doublets $\mathrm{t}=$ triplet and $\mathrm{m}=$ multiplet. Electron impact mass spectra (EI-MS) were recorded on a JEOL JMS-700 spectrometer. Electrospray ionization mass spectra (ESI-MS) were recorded on a Thermo/Finnigan LCQ spectrometer. UVvis absorption and emission spectra were recorded on a Jasco
(V-670) UV-Vis-NIR spectrophotometer and on a Jasco (FP-8500) fluorescence spectrophotometer, respectively. The photoluminescence quantum yields $(\Phi)$ of compounds were performed in THF and water solutions, respectively, relative to a quinine sulfate $\left(\Phi=0.54\right.$ in $\left.0.1 \mathrm{~N} \mathrm{H}_{2} \mathrm{SO}_{4}\right)$ standard. Thermogravimetric analysis was carried out by using a TA instruments TGA Q-500 under a heating rate of $10{ }^{\circ} \mathrm{C} \min ^{-1}$ and

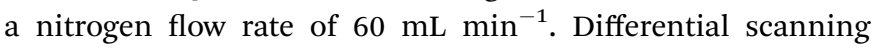
calorimetry (DSC) was carried out using a PerkinElmer DSC 4000 under a heating and a cooling rate of $10{ }^{\circ} \mathrm{C} \mathrm{min}^{-1}$ and a nitrogen flow rate of $20 \mathrm{~mL} \mathrm{~min}{ }^{-1}$. Powder X-ray diffraction (PXRD) data was recorded on a D2 PHASER X-ray Diffractometer with $\mathrm{Cu} \mathrm{K} \alpha$ radiation $(\lambda=1.5418 \AA$ Å). Polarized optical microscopy (POM) images were obtained from Olympus BX51 polarized light microscopy.

Synthesis of 5-fluorobenzo[c] $][1,2,5]$ thiadiazole 1. 4-Fluoro-ophenylenediamine $(2.20 \mathrm{~g}, 17.4 \mathrm{mmol})$ was dissolved in a mixture of $200 \mathrm{~mL}$ of anhydrous $\mathrm{CHCl}_{3}$ and $12 \mathrm{~mL}$ of anhydrous $\mathrm{Et}_{3} \mathrm{~N}$ under an argon atmosphere and then thionyl chloride $(2.8 \mathrm{~mL}, 36.4 \mathrm{mmol})$ was added dropwise by syringe. The mixture was refluxed overnight. The reaction mixture was then cooled down to room temperature and most of the $\mathrm{CHCl}_{3}$ was evaporated. Deionized water $(250 \mathrm{~mL})$ was added to the reaction mixture and then concentrated $\mathrm{HCl}$ was added slowly until the $\mathrm{pH}$ value was 1.0. Through direct steam distillation was used to collect all condensed liquid, extracted three times then dried over anhydrous $\mathrm{MgSO}_{4}$. The solvent was removed by rotary evaporator to give a white solid $(0.88 \mathrm{~g}, 5.7 \mathrm{mmol})$ in a yield of $33 \% .{ }^{1} \mathrm{H}$ NMR $\left(600 \mathrm{MHz}, \mathrm{CDCl}_{3}, \mathrm{ppm}\right) \delta: 7.92(\mathrm{dd}, 1 \mathrm{H}, J=9.6$, $5.4 \mathrm{~Hz}), 7.56(\mathrm{dd}, 1 \mathrm{H}, J=8.6,2.5 \mathrm{~Hz}), 7.37$ (ddd, $1 \mathrm{H}, J=9.6,8.6$, $2.5 \mathrm{~Hz}) .{ }^{13} \mathrm{C}$ NMR $\left(150 \mathrm{MHz}, \mathrm{CDCl}_{3}, \mathrm{ppm}\right) \delta: 163.48\left(\mathrm{~d},{ }^{1} J_{\mathrm{CF}}=253\right.$ $\mathrm{Hz}), 154.87\left(\mathrm{~d},{ }^{3} J_{\mathrm{CF}}=14 \mathrm{~Hz}\right), 151.95,122.49\left(\mathrm{~d},{ }^{3} J_{\mathrm{CF}}=11 \mathrm{~Hz}\right)$, $121.27\left(\mathrm{~d},{ }^{2} J_{\mathrm{CF}}=30 \mathrm{~Hz}\right), 104.76\left(\mathrm{~d},{ }^{2} J_{\mathrm{CF}}=24 \mathrm{~Hz}\right) .{ }^{19} \mathrm{~F}$ NMR $(564$ $\left.\mathrm{MHz}, \quad \mathrm{CDCl}_{3}, \quad \mathrm{ppm}\right) \delta$ : -110.38 . EI-MS: calculated for $\left[\mathrm{C}_{6} \mathrm{H}_{3} \mathrm{FN}_{2} \mathrm{~S}\right]^{+}: m / z 154$, found $m / z 154$.

Synthesis of 5 -fluorobenzo $[c][1,2,5]$ thiadiazole 2 . A similar procedure was used as that described for the synthesis of compound 1 using 1,2-diamino-4,5-difluoro-benzene (2.52 g, $17.4 \mathrm{mmol}$ ) as the starting material. Compound 2 was obtained to give a white solid $(0.92 \mathrm{~g})$ in a yield of $31 \% .{ }^{1} \mathrm{H}$ NMR $(600$ $\left.\mathrm{MHz}, \mathrm{CDCl}_{3}, \mathrm{ppm}\right) \delta: 7.76(\mathrm{dd}, 2 \mathrm{H}, J=9.0,4.5 \mathrm{~Hz}) .{ }^{13} \mathrm{C}$ NMR $(150$ $\left.\mathrm{MHz}, \mathrm{CDCl}_{3}, \mathrm{ppm}\right) \delta: 153.80\left(\mathrm{dd}, 2 \mathrm{C},{ }^{1} J_{\mathrm{CF}}=261 \mathrm{~Hz},{ }^{2} J_{\mathrm{CF}}=20\right.$ $\mathrm{Hz}$ ), 148.85 (pseudo triplet, $2 \mathrm{C},{ }^{3} J_{\mathrm{CF}}=5 \mathrm{~Hz},{ }^{3} J_{\mathrm{CF}}=2 \mathrm{~Hz}$ ), 106.12 $\left(\mathrm{dd}, 2 \mathrm{C},{ }^{2} J_{\mathrm{CF}}=16 \mathrm{~Hz},{ }^{3} J_{\mathrm{CF}}=5 \mathrm{~Hz}\right) .{ }^{19} \mathrm{~F}$ NMR $\left(564 \mathrm{MHz}, \mathrm{CDCl}_{3}\right.$, ppm) $\delta:-128.96$. EI-LRMS: calculated for $\left[\mathrm{C}_{6} \mathrm{H}_{2} \mathrm{~F}_{2} \mathrm{~N}_{2} \mathrm{~S}\right]^{+}: \mathrm{m} / \mathrm{z}$ 172 , found $m / z 172$.

Synthesis of 4,7-dibromo-5-fluorobenzo $[c][1,2,5]$ thiadiazole 3. Compound $1(0.88 \mathrm{~g}, 5.7 \mathrm{mmol})$ and $12 \mathrm{~mL}$ of $48 \% \mathrm{HBr}_{(\mathrm{aq})}$ were charged into a two-neck flask and then bromine was added dropwise with a dropping funnel. The suspension was heated to $120{ }^{\circ} \mathrm{C}$ for 2 days. The suspension was cooled to room temperature and was quenched by saturated aqueous $\mathrm{NaHSO}_{3}$. The mixture was extracted with DCM three times and the combined organic layers were dried over anhydrous $\mathrm{MgSO}_{4}$. The solvent was removed by rotary evaporator and the residue was purified by column chromatography (petroleum ether : $\mathrm{DCM}=8: 2$ ) to give a white solid $(0.82 \mathrm{~g})$ in a yield of $46 \% .{ }^{1} \mathrm{H} \mathrm{NMR}\left(600 \mathrm{MHz}, \mathrm{CDCl}_{3}\right.$, 
ppm) $\delta: 7.79\left(\mathrm{~d}, 1 \mathrm{H}, J_{\mathrm{H}-\mathrm{F}}=8.3 \mathrm{~Hz}\right) .{ }^{13} \mathrm{C} \mathrm{NMR}\left(150 \mathrm{MHz}, \mathrm{CDCl}_{3}\right.$, ppm) $\delta: 160.40\left(\mathrm{~d},{ }^{1} J_{\mathrm{CF}}=256 \mathrm{~Hz}\right), 154.87\left(\mathrm{~d},{ }^{3} J_{\mathrm{CF}}=14 \mathrm{~Hz}\right), 150.33$, $123.88\left(\mathrm{~d},{ }^{2} J_{\mathrm{CF}}=32 \mathrm{~Hz}\right), 114.00\left(\mathrm{~d},{ }^{3} J_{\mathrm{CF}}=11 \mathrm{~Hz}\right), 98.21\left(\mathrm{~d},{ }^{2} J_{\mathrm{CF}}=\right.$ $24 \mathrm{~Hz}) \cdot{ }^{19} \mathrm{~F}$ NMR $\left(564 \mathrm{MHz}, \mathrm{CDCl}_{3}, \mathrm{ppm}\right) \delta:-103.25$. EI-MS: calculated for $\left[\mathrm{C}_{6} \mathrm{H}_{1} \mathrm{Br}_{2} \mathrm{FN}_{2} \mathrm{~S}\right]^{+}: m / z 312$, found $m / z 312$.

Synthesis of 4,7-dibromo-5,6-difluorobenzo[ $c][1,2,5]$ thiadiazole 4. A similar procedure was used as that described for the synthesis of compound 3 using 5 -fluorobenzo[c][1,2,5]thiadiazole $(0.92 \mathrm{~g}, 5.3 \mathrm{mmol})$ as the starting material. Compound 4 was obtained to give a white solid $(0.82 \mathrm{~g})$ in a yield of $47 \% .{ }^{1} \mathrm{H}$ NMR (600 MHz, $\left.\mathrm{CDCl}_{3}, \mathrm{ppm}\right) \delta$ : no peaks. ${ }^{13} \mathrm{C}$ NMR $(150 \mathrm{MHz}$, $\left.\mathrm{CDCl}_{3}, \mathrm{ppm}\right) \delta: 151.84\left(\mathrm{dd}, 2 \mathrm{C},{ }^{1} J_{\mathrm{CF}}=262 \mathrm{~Hz},{ }^{2} J_{\mathrm{CF}}=22 \mathrm{~Hz}\right)$, 148.85 (s, 2C), 99.35 (dd, 2C, $\left.{ }^{2} J_{\mathrm{CF}}=16 \mathrm{~Hz},{ }^{3} J_{\mathrm{CF}}=6 \mathrm{~Hz}\right) .{ }^{19} \mathrm{~F} \mathrm{NMR}$ (564 MHz, $\left.\mathrm{CDCl}_{3}, \mathrm{ppm}\right) \delta$ : -119.53 . EI-MS: calculated for $\left[\mathrm{C}_{6} \mathrm{Br}_{2} \mathrm{~F}_{2} \mathrm{~N}_{2} \mathrm{~S}\right]^{+}: m / z 330$, found $m / z 330$.

Synthesis of 4,4,5,5-tetramethyl-2-(4-(1,2,2-triphenylvinyl) phenyl)-1,3,2-dioxaborolane 5. 1-(4-Bromophenyl)-1,2,2triphenylethylene $(3.00 \mathrm{~g}, 7.3 \mathrm{mmol})$, bis(pinacolato)diboron $(2.24 \mathrm{~g}, 8.8 \mathrm{mmol})$, potassium acetate $(2.87 \mathrm{~g}, 29.2 \mathrm{mmol})$ and $\mathrm{Pd}(\mathrm{dppf}) \mathrm{Cl}_{2}$ (266 mg, $0.36 \mathrm{mmol}$ ) were charged into a two-neck flask and then $30 \mathrm{~mL}$ of anhydrous 1,4-dioxane was added by syringe. The reaction mixture was refluxed under an argon atmosphere for 12 hours. After cooling to room temperature, the catalyst was removed by filtration. The filtrate was extracted with DCM three times and the combined organic layers were dried over anhydrous $\mathrm{MgSO}_{4}$. After removal of the solvent under reduced pressure, the residue was purified by column chromatography (petroleum ether : ether $=9: 1$ ) to give a white solid (2.54 g) in a yield of $76 \% .{ }^{1} \mathrm{H}$ NMR (600 MHz, $\left.\mathrm{CDCl}_{3}, \mathrm{ppm}\right)$

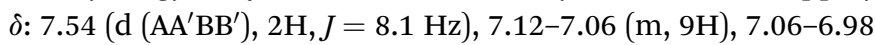
$(\mathrm{m}, 8 \mathrm{H}), 1.32(\mathrm{~s}, 12 \mathrm{H}) .{ }^{13} \mathrm{C} \mathrm{NMR}\left(150 \mathrm{MHz}, \mathrm{CDCl}_{3}, \mathrm{ppm}\right) \delta$ : $146.80,143.73,143.63,143.55,141.42,140.88,134.13,131.38$, 131.35, 131.34, 130.73, 127.76, 127.69, 126.59, 126.49, 126.48, 83.71, 24.94. ESI-MS: calculated for $\left[\mathrm{C}_{32} \mathrm{H}_{31} \mathrm{BO}_{2}\right]^{+}: m / z 459$, found $m / z 459$.

Synthesis of 4,7-bis(4-(1,2,2-triphenylvinyl)phenyl) benzo[c] $[1,2,5]$ thiadiazole BT-2TPE. 4,7-Dibromobenzo[c] $][1,2,5]$ thiadiazole $(0.29 \mathrm{~g}, 1 \mathrm{mmol})$, compound 5 (0.82 g, $1.79 \mathrm{mmol})$, $\mathrm{Pd}\left(\mathrm{PPh}_{3}\right)_{4}(0.11 \mathrm{~g}, 0.1 \mathrm{mmol})$ and potassium carbonate $(1.10 \mathrm{~g}$, $8.0 \mathrm{mmol}$ ) were charged into a two-neck flask under vacuum for 30 minutes. After purging with argon, $80 \mathrm{~mL}$ of toluene, $10 \mathrm{~mL}$ of ethanol and $10 \mathrm{~mL}$ of water was added by syringe. The reaction mixture was refluxed at $120^{\circ} \mathrm{C}$ for 12 hours under an argon atmosphere. After cooling to room temperature, organic solvent was removed by rotary evaporator. The residue was extracted with DCM and water three times and the combined organic layers were dried over anhydrous $\mathrm{MgSO}_{4}$. After removal of the solvent under reduced pressure, the residue was purified by column chromatography (DCM : petroleum ether $=6: 4$ ) to give a yellow solid $(0.68 \mathrm{~g})$ in a yield of $85 \%$. ${ }^{1} \mathrm{H}$ NMR $(600 \mathrm{MHz}$, $\left.\mathrm{CDCl}_{3}, \mathrm{ppm}\right) \delta: 7.78\left(\mathrm{~d}\left(\mathrm{AA}^{\prime} \mathrm{BB}^{\prime}\right), 4 \mathrm{H}, J=8.4 \mathrm{~Hz}\right), 7.74(\mathrm{~s}, 2 \mathrm{H}), 7.20$ $\left(\mathrm{d}\left(\mathrm{AA}^{\prime} \mathrm{BB}^{\prime}\right), 4 \mathrm{H}, J=8.4 \mathrm{~Hz}\right), 7.18-7.05(\mathrm{~m}, 30 \mathrm{H}) .{ }^{13} \mathrm{C} \mathrm{NMR}(150$ $\left.\mathrm{MHz}, \mathrm{CDCl}_{3}, \mathrm{ppm}\right) \delta: 154.01,143.78,143.74,143.65,143.64$, $141.48,140.51,136.26,132.59,131.59,131.47,131.37,131.35$, 128.35, 127.88, 127.81, 127.72, 127.63, 126.58, 126.50, 126.46. HR-MS (EI, $[\mathrm{M}]^{+}$): calculated for $\left[\mathrm{C}_{58} \mathrm{H}_{40} \mathrm{~N}_{2} \mathrm{~S}\right]^{+}: \mathrm{m} / z$ 796.2972, found $m / z$ 796.2970.
Synthesis of 5-fluoro-4,7-bis(4-(1,2,2-triphenylvinyl)phenyl) benzo $[c][1,2,5]$ thiadiazole FBT-2TPE. A similar procedure was used as that described for the synthesis of BT-2TPE using compound 3 (0.25 g, $0.8 \mathrm{mmol})$ as the starting material. The compound FBT-2TPE was obtained to give a yellow solid ( $0.42 \mathrm{~g})$ in a yield of $64 \%$. ${ }^{1} \mathrm{H}$ NMR (600 MHz, DCM-d ${ }_{2}$, ppm) $\delta: 7.79$ $\left(\mathrm{d}\left(\mathrm{AA}^{\prime} \mathrm{BB}^{\prime}\right), 2 \mathrm{H}, J=8.4 \mathrm{~Hz}\right), 7.62\left(\mathrm{~d}, 1 \mathrm{H}, J_{\mathrm{H}-\mathrm{F}}=11.8 \mathrm{~Hz}\right), 7.60$ $\left(\mathrm{d}\left(\mathrm{AA}^{\prime} \mathrm{BB}^{\prime}\right), 2 \mathrm{H}, J=8.4 \mathrm{~Hz}\right), 7.23-7.04(\mathrm{~m}, 34 \mathrm{H}) .{ }^{13} \mathrm{C} \mathrm{NMR}(150 \mathrm{MHz}$, $\left.\mathrm{CDCl}_{3}, \mathrm{ppm}\right) \delta: 133.97,133.34,133.27,131.71,131.48,131.43$, $131.36,131.34,131.31,131.20,129.83,129.81,129.22,128.38$, $127.84,127.79,127.76,127.72,127.65,127.62,126.67,126.61$, $126.57,126.54,126.50,126.46,119.51,119.30,117.11,117.01 .{ }^{19} \mathrm{~F}$ NMR (564 MHz, $\left.\mathrm{CDCl}_{3}, \mathrm{ppm}\right) \delta:-115.14$. HR-MS (EI, $\left.[\mathrm{M}]^{+}\right)$: calculated for $\left[\mathrm{C}_{58} \mathrm{H}_{39} \mathrm{FN}_{2} \mathrm{~S}\right]^{+}: \mathrm{m} / z$ 814.2818, found $\mathrm{m} / \mathrm{z}$ 814.2817.

Synthesis of 5,6-difluoro-4,7-bis(4-(1,2,2-triphenylvinyl) phenyl)benzo[c][1,2,5]thiadiazole 2FBT-2TPE. A similar procedure was used as that described for the synthesis of BT-2TPE using compound $\mathbf{4}(0.25 \mathrm{~g}, 0.75 \mathrm{mmol})$ as the starting material. The compound 2FBT-2TPE was obtained to give a yellow solid $(0.25 \mathrm{~g})$ in a yield of $38 \% .{ }^{1} \mathrm{H}$ NMR $\left(600 \mathrm{MHz}, \mathrm{CDCl}_{3}, \mathrm{ppm}\right) \delta$ : $7.61\left(\mathrm{~d}\left(\mathrm{AA}^{\prime} \mathrm{BB}^{\prime}\right), 4 \mathrm{H}, J=8.4 \mathrm{~Hz}\right), 7.22\left(\mathrm{~d}\left(\mathrm{AA}^{\prime} \mathrm{BB}^{\prime}\right), 4 \mathrm{H}, J=8.4 \mathrm{~Hz}\right)$, 7.20-7.05 (m, 30H). ${ }^{13} \mathrm{C}$ NMR (150 MHz, $\left.\mathrm{CDCl}_{3}, \mathrm{ppm}\right) \delta: 151.27$, 151.13 , 150.39, 150.37, 150.35, 149.55, 149.42, 144.48, 143.60, $143.46,143.45,141.89,140.33,131.45,131.35,131.34,131.32$, $129.79,128.25,127.81,127.76,127.64,126.68,126.56,126.53$, 118.33, 118.31, 118.26, 118.24. $\left.{ }^{19} \mathrm{~F} \mathrm{NMR} \mathrm{(564} \mathrm{MHz,} \mathrm{CDCl}_{3}, \mathrm{ppm}\right)$ $\delta$ : -113.79 . HR-MS (EI, $\left.[\mathrm{M}]^{+}\right)$: calculated for $\left[\mathrm{C}_{58} \mathrm{H}_{38} \mathrm{~F}_{2} \mathrm{~N}_{2} \mathrm{~S}\right]^{+}: \mathrm{m} / z$ 832.2724 , found $m / z$ 832.2725.

\section{Conclusions}

Fluorinated BT linked with TPE were successfully synthesized by a Suzuki-Miyaura cross-coupling reaction using $\mathrm{Pd}\left(\mathrm{PPh}_{3}\right)_{4}$ as the catalyst and $\mathrm{K}_{2} \mathrm{CO}_{3}$ as a base to give the compounds in a moderate yield. All compounds exhibited aggregation-induced emission characteristics upon increasing the water fraction over $60 \%$ in the $\mathrm{THF} /$ water mixtures. In addition, the emission maximum was blue-shifted when the water content reached $90 \%$ compared to the THF solution. The effect of fluorine atoms attached to the central BT unit makes these D-A-D molecules force to be planar which led to a more significant blue-shifted in absorption and emission maximum in the aggregate state. Interestingly, the emission maximum intensity of the compound containing difluorinated BT bonded to two TPE in $90 \%$ water content was found to be 2.5 times higher than that in THF solution which reveal a significant increase in fluorescence compared to that of the unsubstituted and monofluorinated substituted BT. Surprisingly, single crystal with ladder-like packing structures as well as liquid crystal mesophases were observed only for compound comprising of difluorinated BT and TPE. This molecule with the unique feature can be used as a key component in the liquid crystal devices, organic light-emitting diodes and organic field-effect transistors. All compounds showed remarkable solvatochromic effects in various selected solvents with different polarities and revealed notably emission color changes. The powder XRD results and the mechanochromism of the compounds suggested that the solid state structures change from the one form to another. Theses 
compounds will be of tremendous interest to those chemists and physicists interested in fluorescence materials and sensors in general. In addition, fluorescence and sensing ability of compounds including unsubstituted and fluorinated substituted BT bonded to two TPE for explosives analytes is currently under investigation.

\section{Conflicts of interest}

There are no conflicts to declare.

\section{Acknowledgements}

Financial support from the Ministry of Science and Technology and the National Taiwan University of Science and Technology Taiwan is gratefully acknowledged.

\section{Notes and references}

1 H. N. Kim, Z. Guo, W. Zhu, J. Yoon and H. Tian, Chem. Soc. Rev., 2011, 40, 79-93.

2 L. Pu, Chem. Rev., 2004, 104, 1687-1716.

3 J. Wang and X. Qian, Org. Lett., 2006, 8, 3721-3724.

4 K. Acharyya and P. S. Mukherjee, Chem. Commun., 2014, 50, 15788-15791.

5 Y. Ding, Y. Tang, W. Zhua and Y. Xie, Chem. Soc. Rev., 2015, 44, 1101-1112.

6 S. W. Thomas III, G. D. Joly and T. M. Swager, Chem. Rev., 2007, 107, 1339-1386.

7 C.-T. Chen, Chem. Mater., 2004, 16, 4389-4400.

8 G. Qian, Z. Zhong, M. Luo, D. Yu, Z. Zhang, Z. Y. Wang and D. Ma, Adv. Mater., 2009, 21, 111-116.

9 R. Yoshii, A. Hirose, K. Tanaka and Y. Chujo, Chem.-Eur. J., 2014, 20, 8320-8324.

10 Y. Gao, G. Feng, T. Jiang, C. Goh, L. Ng, B. Liu, B. Li, L. Yang, J. Hua and H. Tian, Adv. Funct. Mater., 2015, 25, 2857-2866.

11 R. Yoshii, K. Tanaka and Y. Chujo, Macromolecules, 2014, 47, 2268-2278.

12 M. Liu, P. Gao, Q. Wan, F. Deng, Y. Wei and X. Zhang, Macromol. Rapid Commun., 2017, 38, 1600575.

13 J.-B. Xiong, H.-T. Feng, J.-P. Sun, W.-Z. Xie, D. Yang, M. Liu and Y.-S. Zheng, J. Am. Chem. Soc., 2016, 138, 11469-11472.

14 M. Salimimarand, D. D. La, M. A. Kobaisi and S. V. Bhosale, Sci. Rep., 2017, 7, 42898.

15 Y. Hong, H. Xiong, J. W. Y. Lam, M. Häußler, J. Liu, Y. Yu, Y. Zhong, H. H. Y. Sung, I. D. Williams, K. S. Wong and B. Z. Tang, Chem.-Eur. J., 2010, 16, 1232-1245.

16 A. Ekbote, S. H. Han, T. Jadhav, S. M. Mobin, J. Y. Lee and R. Misra, J. Mater. Chem. C, 2018, 6, 2077-2087.

17 A. Ekbote, T. Jadhav and R. Misra, New J. Chem., 2017, 41, 9346-9353.

18 R. Misra, T. Jadhav, B. Dhokale and S. M. Mobin, Chem. Commun., 2014, 50, 9076-9078.

19 C. Li, X. Luo, W. Zhao, C. Li, Z. Liu, Z. Bo, Y. Dong, Y. Q. Dong and B. Z. Tang, New J. Chem., 2013, 37, 16961699.
20 M. Li, W. Yao, J. Chen, H. Lu, Y. Zhao and C. Chen, J. Mater. Chem. C, 2014, 2, 8373-8380.

21 B. A. D. Neto, A. A. M. Lapis, E. N. da Silva Júnior and J. Dupont, Eur. J. Org. Chem., 2013, 228-255.

22 Y. Wang, X. Xin, Y. Lu, T. Xiao, X. Xu, N. Zhao, X. Hu, B. S. Ong and S. C. Ng, Macromolecules, 2013, 46, 9587-9592.

23 L. Wang, L. Yin, C. Ji and Y. Li, Dyes Pigm., 2015, 118, 37-44.

24 Z. Zhao, C. Deng, S. Chen, J. W. Y. Lam, W. Qin, P. Lu, Z. Wang, Z. Kwok, Y. Ma, H. Qiu and B. Z. Tang, Chem. Commun., 2011, 47, 8847-8849.

25 C. Dou, D. Chen, J. Iqbal, Y. Yuan, H. Zhang and Y. Wang, Langmuir, 2011, 27, 6323-6329.

26 T. Jadhav, B. Dhokale and R. Misra, J. Mater. Chem. C, 2015, 3, 9063-9068.

27 N. Cho, K. Song, J. K. Lee and J. Ko, Chem.-Eur. J., 2012, 18, 11433-11439.

28 E. Buncel and S. Rajagopal, Acc. Chem. Res., 1990, 23, 226231.

29 C. Reichard, Chem. Rev., 1994, 94, 2319-2358.

30 X. Zhang, Z. Ma, Y. Yang, X. Zhang, X. Jia and Y. Wei, J. Mater. Chem. C, 2014, 2, 8932-8938.

31 T. Jadhav, B. Dhokale, Y. Patil, S. M. Mobin and R. Misra, J. Phys. Chem. C, 2016, 120, 24030-24040.

32 M. Irie, Chem. Rev., 2000, 100, 1685-1716.

33 A. Kishimura, T. Yamashita, K. Yamaguchi and T. Aida, Nat. Mater., 2005, 4, 546-549.

34 M. Kinami, B. R. Crenshaw and C. Weder, Chem. Mater., 2006, 18, 946-955.

35 Y. Sagara, T. Mutai, I. Yoshikawa and K. Araki, J. Am. Chem. Soc., 2007, 129, 1520-1521.

36 Y. Ooyama, G. Ito, H. Fukuoka, T. Nagano, Y. Kagawa, I. Imae, K. Komaguchi and Y. Harima, Tetrahedron, 2010, 66, 7268-7271.

37 Y. Ooyama and Y. Harima, J. Mater. Chem., 2011, 21, 83728380 .

38 Y. Sagara and T. Kato, Angew. Chem., Int. Ed., 2008, 47, 51755178.

39 M. Yuan, D. Wang, P. Xue, W. Wang, J. Wang, Q. Tu, Z. Liu, Y. Liu, Y. Zhang and J. Wang, Chem. Mater., 2014, 26, 2467-2477.

$40 \mathrm{H}$. Yu, W. Ren, H. Lu, Y. Liang and Q. Wang, Chem. Commun., 2016, 52, 7387-7389.

41 Z. He, L. Zhang, J. Mei, T. Zhang, J. W. Y. Lam, Z. Shuai, Y. Q. Dong and B. Z. Tang, Chem. Mater., 2015, 27, 6601-6607. 42 H. Li, X. Zhang, Z. Chi, B. Xu, W. Zhou, S. Liu, Y. Zhang and J. Xu, Org. Lett., 2011, 13, 556-559.

43 X. Zhou, H. Li, Z. Chi, X. Zhang, J. Zhang, B. Xu, Y. Zhang, S. Liu and J. Xu, New J. Chem., 2012, 36, 685-693.

44 T. Jadhav, B. Dhokale, Y. Patil, S. M. Mobin and R. Misra, J. Phys. Chem. C, 2016, 120, 24030-24040.

45 S.-K. Kim, Y.-I. Park, I.-N. Kang and J.-W. Park, J. Mater. Chem., 2007, 17, 4670-4678.

46 S. Chen, Y. Li, W. Yang, N. Chen, H. Liu and Y. Li, J. Phys. Chem. C, 2010, 114, 15109-15115.

47 R. Hu, E. Lager, A. Aguilar-Aguila, J. Liu, J. W. Y. Lam, H. H. Y. Sung, I. D. Williams, Y. Zhong, K. S. Wong, E. Pena-Cabrera and B. Z. Tang, J. Phys. Chem. C, 2009, 113, 15845-15853. 